\title{
SELF-SELECTION BIAS IN LONGITUDINAL ESTIMATION OF WAGE GAPS
}

\author{
Gary SOLON * \\ The University of Michigan, Ann Arbor, MI 48109-1220, USA
}

Cross-sectional regression analyses of wage gaps may be biased by omission of unobserved worker characteristics. Recent studies therefore have used longitudinal data to 'difference out' the effects of such variables. This paper, however, shows that self-selection of job changers may cause longitudinal estimation of wage gaps to be inconsistent.

\section{Introduction}

The empirical literature in labor economics abounds with studies of wage gaps between union and non-union workers, workers in safe and dangerous jobs, workers for small and large employers, and so forth. Most of these studies have used cross-sectional data on individual workers to estimate regressions of the wage (or, more commonly, its natural logarithm) on the variable of main interest while attempting the 'hold other things equal' by controlling for a vector of other worker and job characteristics. Despite these efforts to control for other factors, the possibility remains that cross-sectional estimation of wage gaps has been biased by failure to control for unobserved worker characteristics related to both the wage and included regressors. This possibility has motivated a legion of recent researchers to 'difference out' unobserved individual characteristics by estimating fixed-effects models with longitudinal data. This longitudinal literature has grown so rapidly that a full listing of references would be futile, but notable examples include he studies by Freeman (1984) and Mellow (1981) on union-non-union wage differences, Brown (1980) and Duncan and Holmlund (1983) on wage premiums for dangerous or unpleasant working conditions, Brown and Medoff (1985) on wage differences by employer size, Krueger and Summers (1988) on interindustry wage differences, and Madden (1985) on wage differences by length of commuting trip.

The purpose of this paper is to question whether such longitudinal analyses produce consistent estimation of wage gaps. Section 2 motivates the discussion with a graphical exposition of an extreme but illustrative case. Section 3 provides a formal analysis of the general problem - that self-selection of job changers can cause longitudinal estimation to confound the true wage gap with worker taste parameters related to the job changing decision. Section 4 summarizes and discusses the analysis.

\section{An extreme example}

Because the derivation of this paper's main result in Section 3 is rather technical, it is worthwhile first to develop intuition for the result with a simple example. This example, like the analysis throughout this paper, focuses on the simplest longitudinal data structure, one where the sampled

* The author thanks Joseph Altonji, Charles Brown. David Card, David Ellwood, Henry Farber. John Ham. and seminar participants at The University of Michigan, MIT, North Carolina State University, and the National Bureau of Economic Research for their comments. 


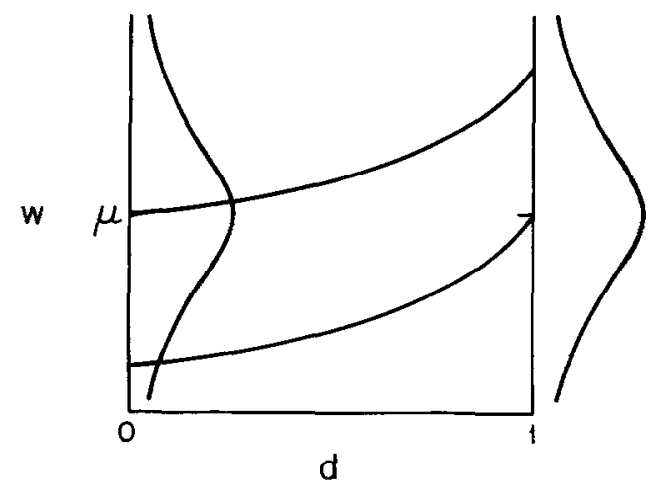

Fig. 1 .

individuals are observed at two points in time. (Most of the studies cited above used data of this type.) With such data, one controls for fixed unobserved worker characteristics simply by 'first-differencing' them out, i.e., by estimating a regression of change in the wage measure on change in the variable of main interest (as well as changes in the control variables). For example, if the relevant wage measure $w$ is the natural logarithm of the wage and $d$ is a dummy variable equal to 1 in dangerous jobs and 0 in safe ones, a longitudinal study of compensating wage differences for dangerous jobs then would examine the relationship between change in $w$ and change in $d$, and would interpret a positive estimated relationship as evidence of compensating differences.

The pitfall in this approach is best illustrated by the following vivid, though implausible, example. Suppose that, despite a universal preference among workers for safe jobs, the market provides no wage premium for dangerous work. This case is illustrated in fig. 1, which measures $w$ on the vertical axis and $d$ on the horizontal axis. The bell-shaped curves represent, for workers of a given skill level, the distributions of market wage opportunities at each safety level. The wage distributions shown for $d=0$ and $d=1$ are alike, representing the absence of any systematic compensating differences.

Now consider a worker initially in a safe $(d=0)$ job. The utility level for this worker - if, for example, his log wage happens to be the mean $\mu$ of the distribution - is represented by the indifference curve ${ }^{1}$ through the point $(\mu, 0)$. Since $w$ is a good and $d$ is a bad, the indifference curve is positively sloped. Consequently, this worker will choose to change to a more dangerous job only if it offers him a substantial wage increase.

In contrast, a worker initially at a dangerous $(d=1)$ job - for example, one whose initial $(w, d)$ pair is $(\mu, 1)-$ may choose to change to a safer job even if it offers a moderately lower wage. As a result, a comparison of job changers is likely to find that those who move from safe to dangerous jobs experience larger wage increases on average than do those who move from dangerous to safe jobs. The self-selection of job changers produces the positive relationship between observed changes in wage and danger even if, as in fig. 1 , the market offers no systematic wage premium for dangerous work.

This example, of course, is quite contrived, but the point it highlights is more generally applicable. Even where the true wage gap between two job types is non-zero and regardless of whether workers prefer one job type to other, self-selection of job changers causes longitudinal estimation of the wage gap to be inconsistent. This point is formally demonstrated in the next section, which analyses a two-sector model of wage variation and job changing.

1 The indifference curve is drawn for expository convenience. Of course, with a dichotomous $d$, only two points on the curve are applicable. 


\section{A formal model}

This section presents a model in which workers work for two periods in either of two sectors. The sectors are indexed by $d=0$ (e.g., for the safe sector, the non-union sector, or the sector with small employers) and $d=1$ (e.g., for the dangerous sector, the union sector, or the large-cmployer sector). Every worker's preferences among jobs are represented by the simple utility function $U=w-\alpha d$ where $w$ is the log wage and $\alpha$ is a taste parameter. In the case where $d=1$ denotes a dangerous job, workers' distaste for dangerous work is represented by a positive $\alpha$. In the case where $d=1$ denotes unionization or a large employer, the sign of $\alpha$ is less clear.

In his first period in the labor market, each worker randomly draws an initial job with log wage $w_{1}$ and sector index $d_{1}$. The probability that he draws a job with $d_{1}=1$ is denoted by $p$; the probability that $d_{1}=0$ is $1-p$. If the worker draws a job with $d_{1}-0, w_{1}$ is drawn from a normal distribution with mean $\mu$ and positive variance $\sigma_{0}^{2}$. As in Jovanovic (1979), the positive variance arises from heterogeneity in the productivity of worker-employer matches. ${ }^{2}$ If the worker draws a job with $d_{1}=1, w_{1}$ is drawn from a normal distribution with mean $\mu+\delta$ and positive variance $\sigma_{1}^{2}$. A non-zero average wage gap $\delta$ between sectors could arise either from non-competitive forces (e.g., from union bargaining in the case of the union-non-union gap) or from competitive forces as is usually supposed in models of compensating wage differences). In the latter case, the equilibrium value of $\delta$ would depend not only on the worker taste parameter $\alpha$, but also on the extent of match heterogeneity in each sector as well as on the determinants of each sector's labor demand. ${ }^{3}$

In his second period in the labor market, each worker makes a new independent draw of another job opportunity $\left(w_{2}, d_{2}\right)$ from the same joint distribution as described above. Define $\Delta w=w_{2}-w_{1}$, $\Delta d=d_{2}-d_{1}$, and $\sigma^{2}=\sigma_{0}^{2}+\sigma_{1}^{2}$. Then

$$
\begin{aligned}
& \Delta d=1 \text { with probability } p(1-p), \\
& =-1 \text { with probability } p(1-p), \\
& \text { - } 0 \text { with probability } 1-2 p(1-p) \text {, }
\end{aligned}
$$

and

$$
\begin{aligned}
& \mathrm{N}\left(\delta, \sigma^{2}\right) \quad \text { if } \Delta d=1, \\
& \Delta w \sim \mathrm{N}\left(-\delta, \sigma^{2}\right) \quad \text { if } \Delta d=-1, \\
& \sim \mathrm{N}\left(0,2 \sigma_{0}^{2}\right) \text { if } \Delta d=0 \text { with } d_{1}=d_{2}=0, \\
& \sim \mathrm{N}\left(0,2 \sigma_{1}^{2}\right) \quad \text { if } \quad \Delta d=0 \quad \text { with } \quad d_{1}=d_{2}=1 .
\end{aligned}
$$

2 An alternative interpretation of the variances $\sigma_{0}^{2}$ and $\sigma_{1}^{2}$, due to Roy $(1951)$, is that they reflect heterugeneity among workers in productivity by sector. If this interpretation were pursued, each worker would face a different wage gap between sectors and, in the remainder of the paper, $\delta$ would be defined as the population average of those wage gaps. The mathematical analysis would be modified only slightly and would end with the same qualitative result that plim $\hat{\delta} \gtreqless \delta$ as $\alpha \gtreqless \delta$.

3 In a conventional static compensating differences model with homogeneous worker preferences, the wage gap is supply-determined by perfectly elastic sectoral labor supply curves at $\delta=\alpha$. Such a model is useless for interpreting longitudinal analyses, however, because it generates no purposeful job changing. As pointed out by Bull and Jovanovic (1988), in models which do generate job changing by incorporating imperfect information and match heterogeneity, sectoral labor supply curves are positively sloped. Their elasticities depend on the magnitude of match heterogeneity in each sector, and the equilibrium wage gap $\delta$ depends also on the positions of the sectoral labor demand curves. 
A worker chooses to change to the newly discovered job if it increases his utility, that is, if $\Delta w>\alpha \Delta d$. Otherwise, the worker stays in his original job. ${ }^{4}$ Consequently, the worker's observed period-to-period change in job characteristics is

$$
\begin{aligned}
\left(\Delta w^{*}, \Delta d^{*}\right)= & (0,0) \quad \text { if } \quad \Delta w \leq \alpha \Delta d \\
& (\Delta w, \Delta d) \text { if } \quad \Delta w>\alpha \Delta d
\end{aligned}
$$

Most longitudinal studies of wage gaps attempt to estimate the average gap $\delta$ by least squares estimation of the regression of $\Delta w^{*}$ on $\Delta d^{*}$. The probability limit of the resulting estimator $\hat{\delta}$ is

$\operatorname{plim} \hat{\delta}=\operatorname{cov}\left(\Delta w^{*}, \Delta d^{*}\right) / \operatorname{var}\left(\Delta d^{*}\right)$,

This probability limit can be easily, though tediously, derived on the basis of well-known properties of truncated normal distributions. ${ }^{5}$ The result, shown below, demonstrates that the self-selection of job changers causes $\hat{\delta}$ to be inconsistent.

In particular, since

$\operatorname{var}\left(\Delta d^{*}\right)=p(1-p)\left\{1-p(1-p)[1-2 \Phi((\alpha-\delta) / \sigma)]^{2}\right.$

and

$\operatorname{cov}\left(\Delta w^{*}, \Delta d^{*}\right)=\delta \operatorname{var}\left(\Delta d^{*}\right)-p(1-p)[1-2 \Phi((\alpha-\delta) / \sigma)]$

$$
\times\left\{2 p(1-p) \sigma \phi((\alpha-\delta) / \sigma)+\sqrt{2} \phi(0)\left[(1-p)^{2} \sigma_{0}+p^{2} \sigma_{1}\right]\right\}
$$

it follows that

$$
\begin{aligned}
\operatorname{plim} \hat{\delta}= & \delta-p(1-p)[1-2 \Phi((\alpha-\delta) / \sigma)] \\
& \times\left\{2 p(1-p) \sigma \phi((\alpha-\delta) / \sigma)+\sqrt{2} \phi(0)\left[(1-p)^{2} \sigma_{0}+p^{2} \sigma_{1}\right]\right\} / \operatorname{var}\left(\Delta d^{*}\right) .
\end{aligned}
$$

Inspection of this expression reveals thal

$\operatorname{plim} \hat{\delta} \gtreqless \sigma \quad$ as $\quad \alpha \gtreqless \delta$.

Thus, the conventional longitudinal estimator of the average wage gap $\delta$ is consistent only in the special and unlikely case that $\delta$ and $\alpha$ are precisely equal.

4 This model assumes unrealistically that all job changing is voluntary. It is true, though, that most job changes are voluntary. For example, household heads in the 1984 Panel Study of Income Dynamics were asked if their present job positions had begun since January 1, 1983. If so, they were asked what happened to their previous positions. If one counts employer closings and relocations, layoffs and firings, and endings of seasonal or temporary jobs as involuntary changes and quits and promotions as voluntary changes, $70 \%$ of the reported job changes are voluntary. The corresponding figure for wives of household heads is $74 \%$. Furthermore, the overwhelming majority of changers indicated that their present jobs were better than their previous jobs. See pages 197-198 and 259 of Survey Research Center (1986).

5 For a step-by-step derivation of the probability limit, see Solon (1986). 


\section{Summary and discussion}

This paper has presented a simple model to illustrate the inconsistency of conventional longitudinal estimation of wage gaps. The problem is that identification of wage gaps in longitudinal studies depends mainly on wage changes of job changers, who are largely a self-selected group.

One obvious application of the previous section's analysis is to longitudinal estimation of union-non-union wage differences. In fact, the self-selection issue in this context has already been discussed by Freeman (1984). Freeman's discussion, however, pertains to a different estimator of $\delta$ and also implicitly assumes that $\alpha=0$, i.e., that, given equal wages, workers are indifferent between union and non-union jobs. In that case, he finds that longitudinal analysis tends to underestimate the true $\delta$. The previous section's result clearly leads to the same conclusion in that case: if $\alpha=0$ and $\delta>0$, then $\delta>\alpha$ and hence plim $\hat{\delta}<\delta$. But the present paper's analysis can be generalized to cases of non-zero $\alpha$ as well. Several writers ${ }^{6}$ have proposed reasons other than higher wages (such as non-wage benefits and protection against arbitrary management practices) for why workers might prefer union jobs. These factors suggest that $\alpha<0$, which just strengthens the conclusion that $\delta>\alpha$ and $\operatorname{plim} \hat{\delta}<\delta$. Furthermore, even if $\alpha>0$ (that is, workers have a distaste for unionized employment), as long as $\alpha$ is less than $\delta$, the downward inconsistency of $\hat{\delta}$ still applies.

Another application is to the large literature that attempts to test the theory of compensating wage differences. Much of this literature focuses on whether wage premiums appear in jobs with high risk of injury or death. As Smith (1979) explains, this focus is necessary because the theory generates a refutable hypothesis that compensating differences must prevail only in cases of job characteristics universally regarded as disagreeable. These studies then maintain the hypothesis that workers prefer safe jobs (i.e., $\alpha>0$ ) and test a null hypothesis that, despite such preferences, no compensating differences arise (i.e., $\delta=0$ ). This null hypothesis corresponds exactly to the example discussed in section 2. As claimed there and proved in section 3, if $\delta=0$ and $\alpha>0$, then $\alpha>\delta$ and plim $\hat{\delta}>\delta=0$. Thus, longitudinal studies would tend to 'corroborate' the theory of compensating differences even if it were false. Furthermore, in the more plausible case that the theory has some validity, longitudinal estimation of the magnitude of $\delta$ remains generally inconsistent.

Finally, lest the results in this paper be used too confidently for determining the signs of estimators' inconsistencies or for devising new estimators, it is worth emphasizing the special nature of the analysis. This paper's model assumes that all job changing is voluntary and is guided by a particular arbitrary utility function and job changing rule. Furthermore, the analysis pertains to only two periods, and the model of wage dispersion involves arbitrary normality assumptions. The analysis is therefore far from definitive; rather, it gives an illustration of how self-selection of job changers can distort longitudinal cstimation of wage gaps.

\section{References}

Brown, Charles, 1980, Equalizing differences in the labor market, Quaterly Journal of Economics 94, 113-134.

Brown, Charles and James L. Medoff, 1985, The employer size wage effect, unpublished manuscript.

Bull, Clive and Boyan Jovanovic, 1988, Mismatch versus derived-demand shift as causes of labour mobility, Review of Economic Studies 55, 169-175.

Duncan, Greg J. and Bertil Holmlund, 1983, Was Adam Smith right after all? Another test of the theory of compensating wage differentials, Journal of Labor Economics 1, 366-379.

Farber, Henry S. and Daniel H. Saks, 1980, Why workers want unions: The role of relative wages and job characteristics, Journal of Political Economy 88, 439-369.

6 See, for example, Rees (1977), Farber and Saks (1980), and Freeman and Medoff (1984). 
Freeman, Richard B., 1984, Longitudinal analyses of the effects of trade unions, Journal of Labor Economics 2, 1-26. Freeman, Richard B. and James L. Medoff, 1984, What do unions do? (Basic Books, New York).

Jovanovic, Boyan, 1979, Job matching and the theory of turnover, Journal of Political Economy 87, 972990.

Krueger, Alan B. and Lawrence H. Summers, 1988, Efficiency wages and the inter-industry wage structure, Econometrica 56, 259-293.

Madden, Janice Fanning, 1985, Urban wage gradients: Empirical evidence, Journal of Urban Economics 18, $291-301$.

Mellow, Wesley, 1981, Unionism and wages: A longitudinal analysis, Review of Economics and Statistics 63, 43-52.

Rees, Albert, 1977, The economics of trade unions, second ed. (University of Chicago Press, Chicago, IL).

Roy, A.D., 1951, Some thoughts on the distribution of earnings, Oxford Economic Papers 3, 135-146.

Smith, Robert S., 1979, Compensating wage differentials and public policy: A review, Industrial and Labor Relations Review $32,339-352$.

Solon, Gary, 1986, Bias in longitudinal estimation of wage gaps, Technical working paper no. 58 (National Bureau of Economic Research, New York).

Survey Research Center, 1986, A panel study of income dynamics: Procedures and tape codes, 1984 interviewing year - Wave XVII, a supplement (Institute for Social Research, The University of Michigan, Ann Arbor, MI). 